\title{
Pesticides induced oxidative stress in thymocytes
}

\section{Selen Olgun ${ }^{1}$ and Hara P. Misra ${ }^{1,2}$}

${ }^{1}$ Edward Via Virginia College of Osteopathic Medicine, Virginia Tech CRC, 2265 Kraft Drive, Blacksburg, VA 24060, USA; ${ }^{2}$ Department of Biomedical Sciences and Pathobiology, College of Veterinary Medicine, Virginia Polytechnic Institute and State University, Blacksburg, VA 24061, USA

\section{Erratum to: Molecular and Cellular Biochemistry}

DOI: 10.1007/s11010-006-9178-7

In the HTML version of this article the name of the first author should be written as 'Olgun'. 